\title{
PURIFICACIÓN Y CARACTERIZACIÓN DE LA L-AMINO ÁCIDO OXIDASA DEL VENENO DE LA SERPIENTE Bothrops brazili "JERGÓN SHUSHUPE"
}

\author{
PURIFICATION AND CHARACTERIZATION OF AN L-AMINOACID OXIDASE \\ FROM VENOM OF THE SNAKE Bothrops brazili "JERGON SHUSHUPE"
}

\author{
Christian Solís ${ }^{1}$, Enrique Escobar ${ }^{1}$, Armando Yarlequé ${ }^{1}$ y Susana Gutiérrez ${ }^{2}$.
}

\section{RESUMEN}

Se ha purificado y caracterizado parcialmente la L-aminoácido oxidasa de la serpiente Bothrops brazili. El aislamiento se realizó usando técnicas cromatográficas en Sephadex G-100 y CM-Sephadex C-50, utilizando como eluyente buffer acetato de amonio $0,1 \mathrm{M} \mathrm{pH6}$. La enzima fue purificada 29,3 veces con un rendimiento de $30,9 \%$. Usando electi oforesis en gel de poliacrilamida con dodecil sulfato de sodio (PAGESDS) en condiciones reductoras y no reductoras, así como las técnicas de inmunodifusión e inmunoelectroforesis, se demostró la presencia de una sola banda proteica. La enzima fue caracterizada como una glicoproteína ácida con un peso molecular de 125,7 kd formada por dos subunidades de 59,9 kd unidas por enlaces débiles, con un pH óptimo entre 7,5 y 9, dependiendo del aminoácido usado como substrato; siendo termoestable hasta los $55^{\circ} \mathrm{C}$ y lábil a pH alcalino. Asimismo, los ensayos por el método del cilindro en placa de Grove demostraron el efecto antibacteriano de la proteína aislada en cepas estandarizadas de Staphylococcus aureus, Vibrio cholerae y Streptococcus faecalis.

Palabras claves: L-aminoácido oxidasa, Bothrops brazili, veneno, antibacteriano, proteína.

\section{ABSTRACT}

An L-aminoacid oxidase was purified from Bothrops brazili snake venom using Sephadex G-100 and CM-Sepahdex $\mathrm{C}-50$ chromatographic method; in both cases $0,1 \mathrm{M}$ ammonium acetate $\mathrm{pH} 6$ was used as a eluted. The enzyme was purified 29,3 fold with $30,9 \%$ of yield. A homogeneus protein band was achieved by PAGE-SDS, inmunodifusion as well as immunoelectrophoresis. The enzyme was an acid glicoprotein with a molecular weight of 125,7 kd consisting of two subunits of $59,91 \mathrm{kd}$ each, linked by noncovalent bonds. The optimum $\mathrm{pH}$ was in the range of 7,5 to 9,0 depending on the L-aminoacid used as substrate. It was a thermoestabie protein untill $55^{\circ} \mathrm{C}$, but its activity decreased by alcaline treatment. On the other hand, antibacterial assays using the Grove's method demonstrated that the whole venom as well as its purified enzyme produced a severe action on standardized grown cultures of Staphylococcus aureus, Vibrio cholerae and Streptococcus faecalis.

Key words: L-amino acid oxidase, Bothrops brazili, venom, antibacterial, protein.

\section{INTRODUCCIÓN}

Las L-aminoácido oxidasas (EC.1.4.3.2) catalizan la desaminación oxidativa de los Laminoácidos y producen un cetoácido, amoníaco y peróxido de hidrógeno. Estas enzimas

\footnotetext{
'Laboratorio de Biología Molecular. Facultad de Ciencias Biológicas. UNMSM.

${ }^{2}$ Laboratorio de Fisiología y Ecología Microbiana.

Facultad de Ciencias Biológicas. UNMSM.
}

están ampliamente distribuidas en la naturaleza y han sido descritas en bacterias, levaduras, hepatopáncreas de moluscos, huevos de gusano de seda, riñones de mamíferos, hígado de aves y mamíferos, y venenos de algunos reptiles, incluyendo ofidios de las familias Elapidae y Viperidae (Meister,1965; Nakano et al., 1969; Stiblova y Kornalick,1967; Tu, 1977).

A pesar de que su función biológica ha sido 
poco comprendida, esta enzima posee una potencial utilidad en la investigación bioquímica, y ha sido utilizada en la identificación de Laminoácidos (Avrameas y Uriel,1965), en la preparación de a-cetoácidos (Buckey y Porges, 1956), en la obtención de FAD (Singer y Kearney, 1950), en la obtención de Daminoácidos (Parikh et al.,1951) y en la determinación de la actividad de otras enzimas, como las peptidasas (Donlon y Fottrell,1971).

En venenos de serpientes, su rol aunque aún poco estudiado, podría estar relacionado con la degradación de aminoácidos durante la digestión, así como con la protección contra microorganismos presentes en la presa ingerida (Yarlequé et al., 1997). El color amarillo característico de algunos venenos se debe a la presencia de esta enzima, ya que ella posec FAD como cofactor.

Nuestras investigaciones previas sobre la acción antibacteriana de la L-aminoácido oxidasa encontrada en los venenos de Lachesis muta, B. atrox y B. pictus (Yarlequé et $a l ., 1997)$, motivaron el presente estudio, destinado a caracterizar la enzima en la ponzoña de $B$. brazili, serpiente que habita en la selva norte del Perú y que, por el gran volumen de veneno que puede producir (2-4 ml), constituye una fuente biológica de especial interés en la búsqueda de principios bioactivos de utilidad médica.

\section{MATERIAL Y MÉTODOS}

En esta investigación se utilizó veneno cru- do de ejemplares adultos de la serpiente $B$. brazili, procedentes de la zona del Alto Marañón y mantenidos en cautiverio en el serpentario Oswaldo Meneses del Museo de Historia Natural de la Universidad Nacional Mayor de San Marcos. El veneno extraído por presión manual de las glándulas fue liofilizado y conservado a $-8^{\circ} \mathrm{C}$.

La actividad de L-aminoácido oxidasa se determinó a $37^{\circ} \mathrm{C}$, por el método descrito en el Worthington Enzyme Manual (1977). La mezcla de reacción conienía $50 \mu$ de peroxidasa $0,007 \%$ y $1 \mathrm{ml}$ de buffer Tris $\mathrm{HCl}$ $0,2 \mathrm{M} \mathrm{pH} 7,5$ que contenía L-leucina $0,1 \%$ y 0 -dianisidina $0,0065 \%$. Luego de agregar 25 $\mu l$ de la enzima, se midió el incremento de la absorbancia a $436 \mathrm{~nm}$. La actividad específica se expresó en U/mg de proteína. Una unidad, oxida $1 \mu \mathrm{mol}$ de L-leucina por minuto en las condiciones especificadas.

La estabilidad al pH de la enzima en el veneno crudo se determinó usando buffer acetato de amonio 0,1 $\mathrm{M} \mathrm{pH} \mathrm{5,6} \mathrm{y} \mathrm{7,} \mathrm{y} \mathrm{buffer} \mathrm{Tris}$ HCl 0,1 M pH 8 y 9 . En cada caso se mezcló $0,8 \mathrm{ml}$ de buffer y $0,2 \mathrm{ml}$ del veneno crudo 5 $\mathrm{mg} / \mathrm{ml}$ a temperatura ambiente, y se midió la actividad enzimática a las 0,48 y 90 horas.

La purificación de la enzima se hizo a partir de $75 \mathrm{mg}$ de veneno liofilizado disueltos en $1,5 \mathrm{ml}$ de buffer acetato de amonio $0,1 \mathrm{M} \mathrm{pH}$ 6 y centrifugados a 4000 rpm durante $15 \mathrm{mi}$ nutos. $1 \mathrm{ml}$ del sobrenadante fue aplicado a una columna de Sephadex G-1.00 (1,2 x 50 $\mathrm{cm}$ ) equilibrada con el mismo buffer y a un flujo de $7 \mathrm{ml} / \mathrm{h}$. Se colectaron fracciones de 2

Tabla 1. Estabilidad a diferentes pH de la L-aminoácido oxidasa del veneno crudo de $B$. brazili

\begin{tabular}{cccc}
\hline H & \multicolumn{3}{c}{ \% de actividad enzimática } \\
\cline { 2 - 4 } & $\mathbf{0 ~ h o r a s ~}$ & $\mathbf{4 8 \text { horas }}$ & $\mathbf{9 6 \text { horas }}$ \\
\hline 5 & 99,19 & 100,61 & 99,16 \\
6 & 100,00 & 110,47 & 103,55 \\
7 & 92,73 & 100,93 & 99.19 \\
8 & 82,46 & 0,00 & 0,00 \\
9 & 10,17 & 0,00 & 0,00 \\
\hline
\end{tabular}


Tabla 2. Tabla de purificación de la L-aminoácido oxidasa de $B$. brazili

\begin{tabular}{cccccc}
\hline Etapa & $\begin{array}{c}\text { Proteína } \\
(\mathbf{m g})\end{array}$ & $\begin{array}{c}\text { Act.Esp. } \\
(\mathbf{U} / \mathbf{m g})\end{array}$ & $\begin{array}{c}\text { Unid.Tot. } \\
\text { Actv. }\end{array}$ & Purificación & $\begin{array}{c}\text { Rendimiento } \\
(\boldsymbol{\%})\end{array}$ \\
\hline Crudio & 54,45 & 0,19 & 10,81 & 1,0 & 100,00 \\
Sephadex G-100 & 4,70 & 1,07 & 5,04 & 5,4 & 46,7 \\
$\begin{array}{c}\text { CM-Sephadex } \\
\text { C-50 }\end{array}$ & 0,59 & 5,58 & 3,33 & 29,3 & 30,9 \\
\hline
\end{tabular}

ml, determinándose en ellas la concentración de proteína y la actividad de L-aminoácido oxidasa. Las fracciones con mayor actividad específica fueron reunidas y aplicadas a una columna de CM-Sephadex C-50 (1,8 x 13,8 $\mathrm{cm}$ ) equilibrada con el buffer anterior y a un flujo de $17 \mathrm{ml} / \mathrm{h}$. Las proteínas retenidas en la columna fueron eluidas con el mismo buffer que contenía $\mathrm{NaCl} 1,0 \mathrm{M}$. Se colectaron fracciones de $1 \mathrm{ml}$ y aquellas con actividad de Laminoácido oxidasa fueron utilizadas para su estudio.
Durante la purificación, la proteína se determinó a $280 \mathrm{~nm}$ por el método de Warburg y Christian (1941). En la enzima purificada, el contenido de proteína fue estimado por el método de Lowry, usándose albúmina bovina como referencia (Lowry et al., 1951).

Con la finalidad de evaluar la pureza y el peso molecular de la enzima, se empleó electroforesis en gel de poliacrilamida con dodecil sulfato de sodio (PAGE-SDS) en presencia y ausencia de $\beta$-mercaptoetanol (Weber

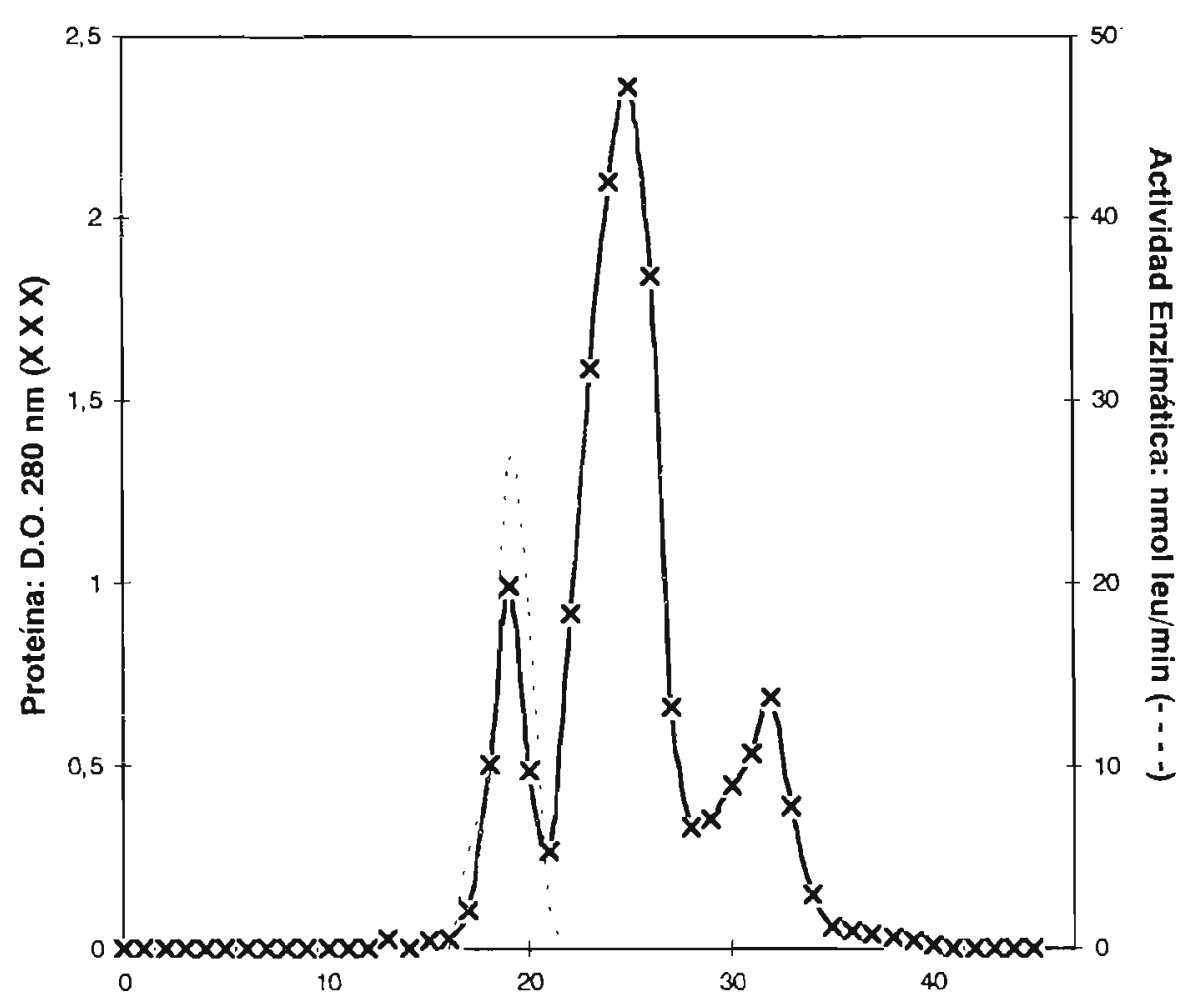

NO. DE FRACCION

Figura 1. Fraccionamiento del veneno de B. brazili en Sephadex G-100 y separación de la Laminoácido oxidasa. 


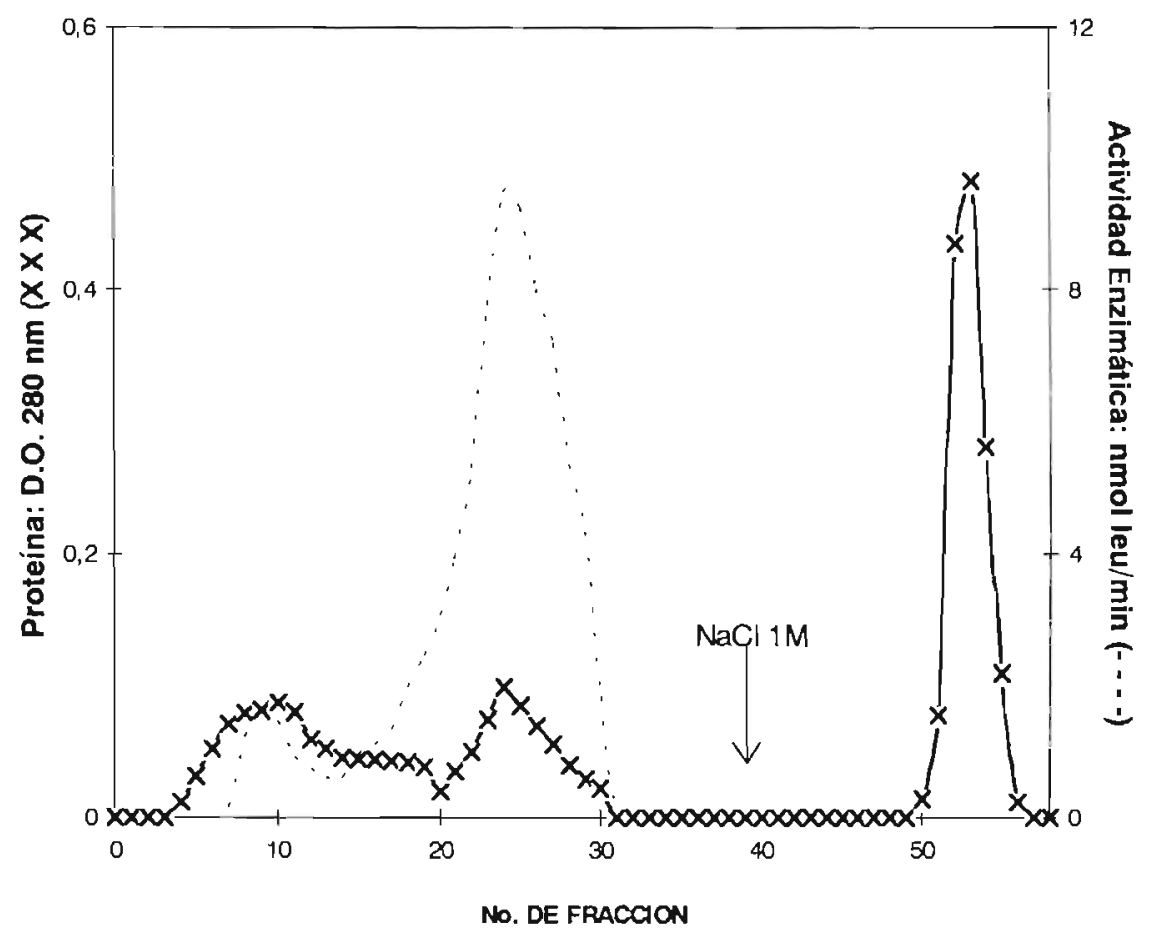

Figura 2. Aislamiento de la L-aminoácido oxidasa en CM-Sephadex C-50.

y Osborn, 1969). La pureza de la enzima también se determinó por inmunoelectroforesis e inmunodifusión (Ouchterlony y Nilsson,1986). El peso molecular de la enzima fue calculado además por cromatografía de filtración (Andrews, 1964) utilizando una columna de Sephadex G-200 (2,1 x 16,1 cm) equilibrada con acetato de amonio $0,1 \mathrm{M}$ pH 6 .

En cuanto al contenido de carbohidratos presentes en la enzima aislada, las hexosas fueron determinadas por el método de Dubois et al. (1956), mientras que las hexosaminas se determinaron por el método de Winsler (1955). La determinación de ácidos siálicos se hizo de acuerdo al método de Warren (1959).

Para estudiar la termoestabilidad de la enzima, se preincubaron alícuotas de $30 \mu$ entre 37 y $95^{\circ} \mathrm{C}$ durante 10 minutos, luego de lo cual se enfriaron bruscamente a $4{ }^{\circ} \mathrm{C}$ durante 3 minutos para medir la actividad enzimática.

El efecto del $\beta$-mercaptoetanol se evaluó preincubando a $37^{\circ} \mathrm{C}$ durante 15 minutos, 20 wl de la enzima con $20 \mu \mathrm{l}$ de $\beta$-mercaptoetanol (10 y $20 \mathrm{mM}$ ), luego de lo cual se midió la actividad enzimática con $30 \mu \mathrm{l}$ de la mezcla.

El pH óptimo de la enzima se determinó usando los siguientes L-aminoácidos como sustratos: leucina, metionina fenilalanina, triptofano, lisina e isoleucina. Para los ensayos se utilizaron los buffers acetato de amonio, Tris- $\mathrm{HCl}$ y glicina a concentración de $0,1 \mathrm{M} \mathrm{y}$ en un rango de $\mathrm{pH}$ de 5 a 11.

Para estudiar el efecto antibacteriano del veneno crudo y la enzima purificada, se usaron cepas de Staphylococcus aureus ATCC 6538, Streptococcus faecalis INS CP696 y Vibrio cholerae serotipo Inaba INS, de acuerdo al método del cilindro en placa (Grove y Randall,1955).

\section{RESULTADOS Y DISCUSION}

Los resultados de la estabilidad de la enzi- 


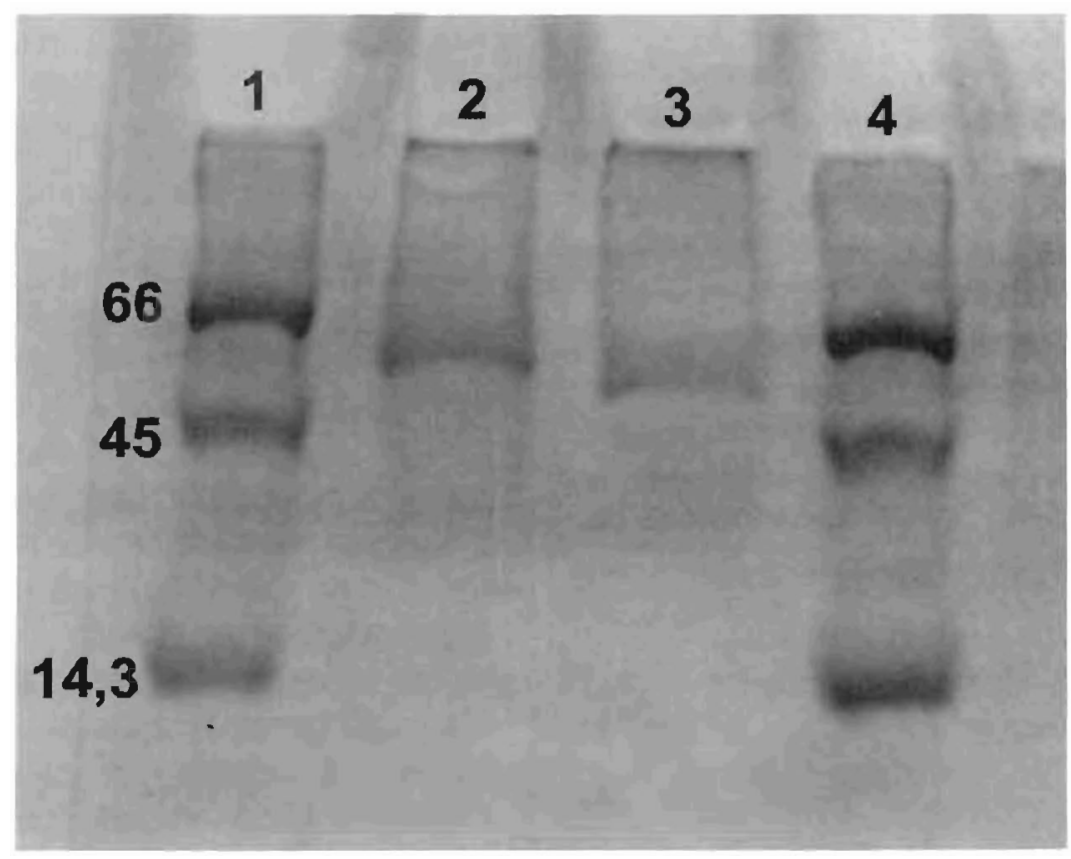

Figura 3. PAGE-SDS de la L-aminoácido oxidasa aislada del veneno de $B$. brazili. En los carriles 1 y 4 se observan los estándares de peso molecular: albúmina ( $66 \mathrm{kd}$ ), ovoalbúmina (45 $\mathrm{kd})$ y lisozima $(14,3 \mathrm{kd})$. En los carriles 2 y 3 se muestra la enzima reducida $(59,9 \mathrm{kd})$ y no reducida $(54,3 \mathrm{kd})$, respectivamente.

ma a diferentes $\mathrm{pH}$, en el veneno crudo, se muestran en la Tabla 1. Se observa qte la enzima es estable a pH 5,6 y 7 , mientras que a pH 8 y 9 la actividad se pierde rápidamente. Esto nos permitió seleccionar el buffer acetato de amonio $0,1 \mathrm{M}$ a pH 6 para realizar el aislamiento de la enzima. El procedimiento desarrollado para aislar la L-aminoácido oxidasa comprendió el uso de una columna de Sephadex G-100 seguida de un intercambio catiónico en CM-Sephadex C-50, lográndose finalmente una purificación de 29,3 veces y un rendimiento de $30,9 \%$, tal como se muestra en la Tabla 2. Al pasar el veneno crudo a través de la columna de Sephadex G-100 se obtuvo un perfil cromatográfico con 3 picos de proteína (Figura 1), y se encontraron las fracciones con actividad de L-aminoácido oxidaasa en el primer pico. Cuando estas fracciones se pasaron a través de la columna de CM-Sephadex C-50, se obtuvieron dos picos de proteína eluidos directamente y un pico adicional al usar el buffer de elución con $\mathrm{NaCl}$
$1 \mathrm{M}$ (Figura 2); se encontró la mayor actividad enzimática en el segundo pico. El hecho de que la actividad de la enzima se detecte en el primer pico de proteína obtenido en la cromatografía usando Sephadex G-100, y de que eluya directamente de la columna de $\mathrm{CM}$ Sephadex C-50 a pH 6, nos revela que se trata de una de las proteínas de mayor peso molecular del veneno y que además posee un punto isoeléctrico (pI) menor a 6, respectivamente. El método de purificación usado, además de su sencillez, nos ofrece la ventaja de que el primer paso de purificación constituye también la etapa inicial para el aislamiento de otras enzimas tales como fosfolipasa, similar a trombina y fibrinogenolítica (Zeballos, 1996; Liman et al.,1996; Azañero, 1996).

El análisis de pureza efectuado por PAGESDS mostró una sola banda proteica (Figura 3), y los resultados de la inmunodifusión e inmunoelectroforesis mostraron una sola línea de precipitación para la enzima aislada (Figura 4). 


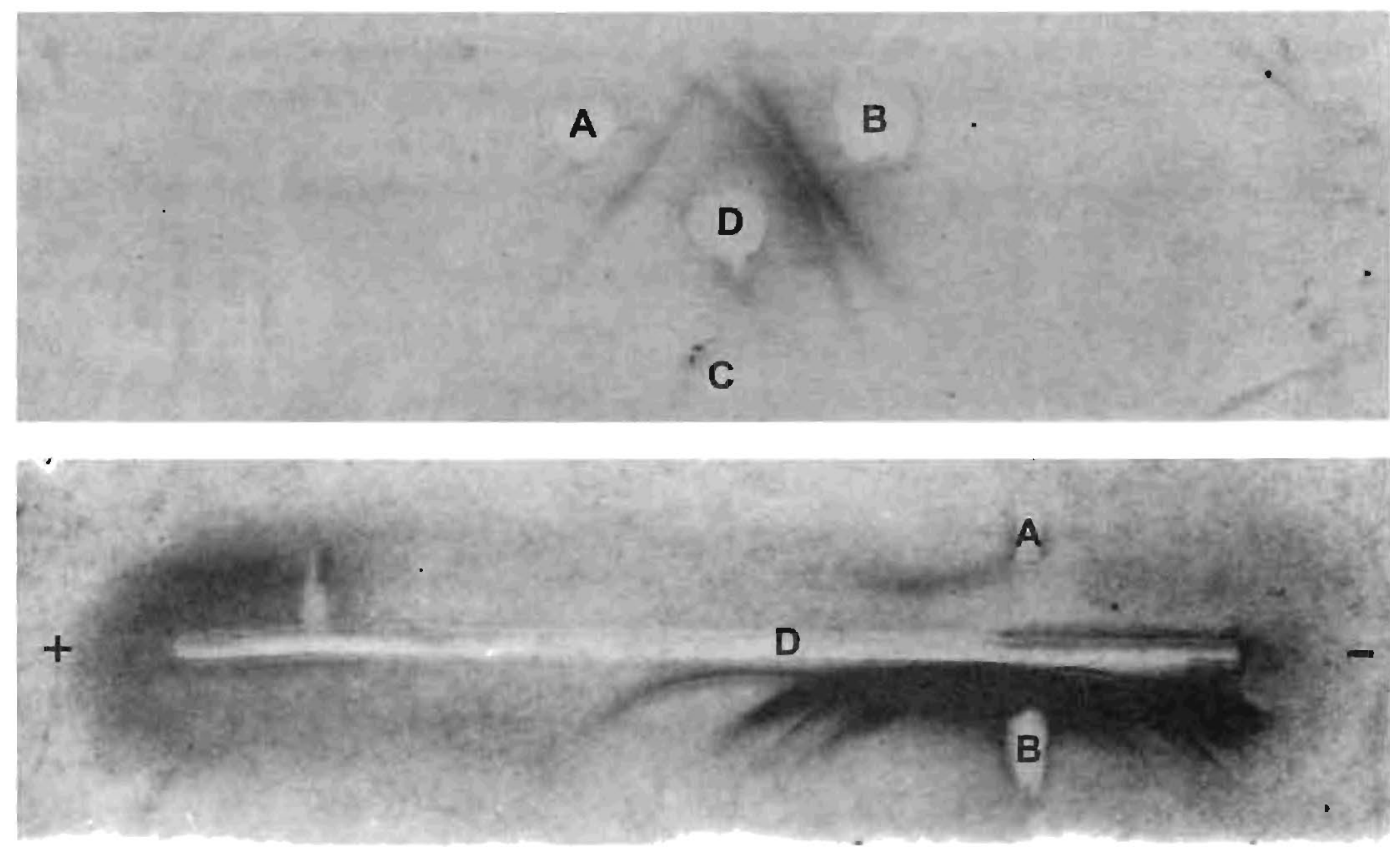

Figura 4. Inmunodifusión e inmunoelectroforesis. Se observan las líneas de precipitación obtenidas luego de la inmunodifusión (parte superior), e inmunoelectroforesis (parte inferior). A: Laminoácido oxidasa, B: veneno crudo de $B$. brazili, $C$ : peroxidasa de rabanito, y $\mathrm{D}$ : suero antibotrópico polivalente.

El peso molecular de la enzima calculado por cromatografía de filtración fue de 125,7 $\mathrm{kd}$ y por PAGE-SDS en condiciones reductoras y no reductoras, $59,9 \mathrm{kd}$ y $54,3 \mathrm{kd}$ respectivamente. Esto nos sugiere que la L-aminoácido oxidasa de $B$. brazili es un dímero no covalente con un peso molecular de $125,7 \mathrm{kd}$, y cadenas polipeptídicas de 59,9 kd cada una, las cuales tienen al menos un enlace disulfuro intracatenario. El peso molecular calculado está dentro del intervalo de pesos moleculares descritos para L-aminoácido oxidasas de otros venenos de serpientes (Iwanaga y Suzuki,1979).

El contenido de hexosas, hexosaminas y ácido siálico fue de $1,86,0,47$ y $0,31 \%$ respectivamente en el veneno crudo, y $15,7,2,40$ y $0,74 \%$ respectivamente, en la enzima purificada. Esto nos revela que la enzima es una glicoproteína, hecho evidenciado también en las enzimas de Crotalus adamanteus (Dekok y Rawitch,1969), Lachesis muta (Sánchez y Magalhaes,1991) y Ophiophagus hannah (Li et al., 1994). Las cadenas de oligosacáridos de la enzima no sólo modularían sus propiedades fisicoquímicas, tales como solubilidad, viscosidad, estabilidad y carga, sino que también la protegerían de la proteólisis, teniendo en cuenta el entorno fuertemente proteolítico de la enzima en el veneno (Dos Santos et al.,1993).

La enzima se mostró resistente al tratamiento térmico hasta los $55^{\circ} \mathrm{C}$, reduciendo su actividad al $43,02 \%$ a los $65^{\circ} \mathrm{C}$ y perdiéndola totalmente a $\operatorname{los} 75^{\circ} \mathrm{C}$ (Figura 5). Esto contrasta con lo hallado para la L-aminoácido oxidasa de la serpiente Agkistrodon piscivorus, en la que el grado de inactivación por la temperatura se incrementa progresivamente de 25 a 45 ${ }^{\circ} \mathrm{C}$ (Minton y Minton, 1970).

El $\beta$-mercaptoetanol, agente reductor capaz 


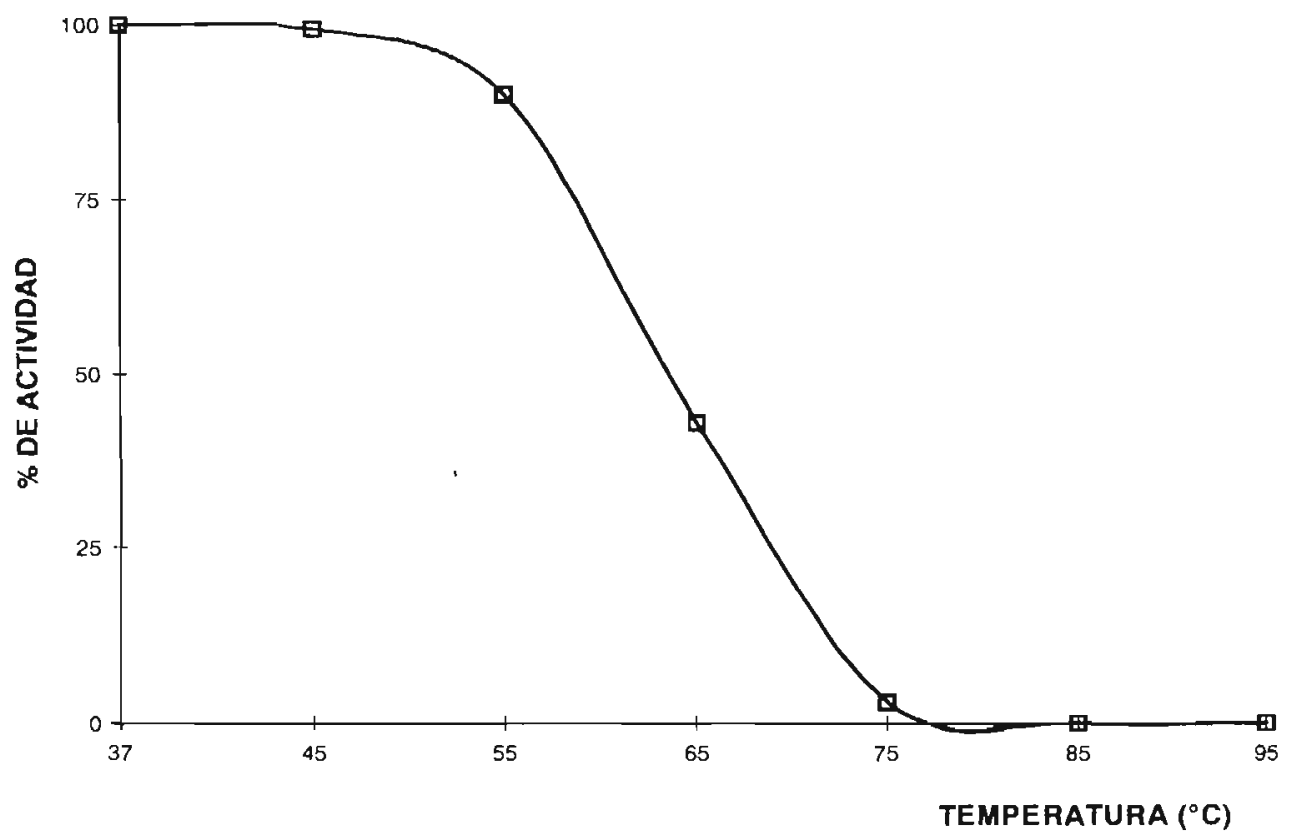

Figura 5. Termoestabilidad de la L-aminoácido oxidasa de B. Brazili.

de escindir enlaces disulfuro, inhibió la actividad de la enzima purificada en un 93 y $94 \%$ a 10 y $20 \mathrm{mM}$ respectivamente, de lo que se infiere que los enlaces disulfuro intracatenarios demostrados por PAGE-SDS son esenciales para mantener su estructura y función.

Al estudiar el pH óptimo de la enzima se encontraron 6 diferentes curvas de $\mathrm{pH}$, dependiendo del aminoácido usado como substrato. Fl pH óptimo con leucina, metionina y fenilalanina fue de 8,5 , con isoleucina fue 8 , con triptofano fue 7,5 y con lisina 9,0. Estas diferentes curvas de $\mathrm{pH}$ son la resultante del comportamiento ácido base de la enzima frente a los distintos comportamientos ácido base de los substratos. En el pH óptimo, tanto la enzima como el substrato exhiben un equilibrio iónico en particular que permite que exista la mayor probabilidad de que el substrato encaje, sea mantenido firmemente en el centro activo y esté orientado correctamente respecto a los grupos catalíticos de la enzima, para que tenga lugar la reacción.

Como en la mayoría de las enzimas, las curvas de $\mathrm{pH}$ óptimo obtenidas son acampa- nadas. Esto es el resultado de las titulaciones de por lo menos dos grupos funcionales presentes en el sitio activo de la enzima. Se observa que en la mayoría de los casos se obtiene un 50\% de actividad enzimática en las partes ascendentes de las curvas a $\mathrm{pH} 7$ y 7,5 y en las partes descendentes a $\mathrm{pH} 9,5$ y 10 , 10 que nos sugiere que la actividad de la Laminoácido oxidasa depende de residuos de aminoácidos cuyos grupos funcionales en el sitio activo tienen valores de $\mathrm{pK}$ alrededor de 7 y 10 . El grupo imidazol de la histidina ha sido sugerido en otras L-aminoácido oxidasas como parte del centro activo, en base a estudios cinéticos comparativos usando $\mathrm{H}_{2} \mathrm{O}$ y $\mathrm{D}_{2} \mathrm{O}$ (Page y Etten,1971), estudios de inactivación reversible (Coles et al.,1980) y estudios de unión de inhibidores (Dekok y Veeger, 1968).

Además tanto el veneno crudo como la enzima aislada fueron capaces de inhibir el crecimiento de $S$. aureus, $V$. cholerae y $S$. faecalis (Figura 6). Este efecto ha sido también observado son L-aminoácido oxidasas de otras serpientes tales como Crotalus adamanteus "cascabel norteamericana" (Skarnes,1970) y Pseudechis australis "rey pardo australiano" 


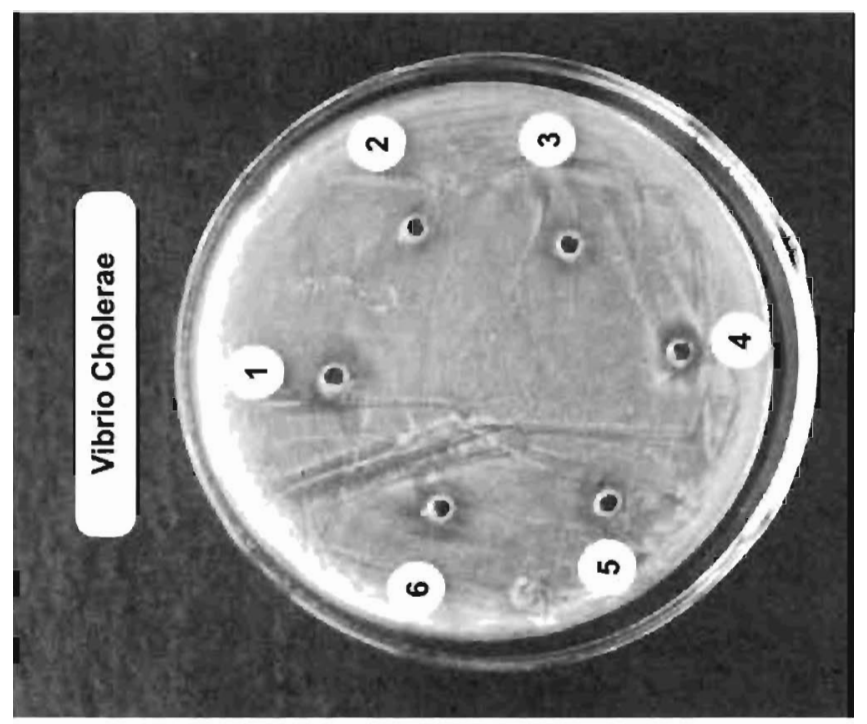

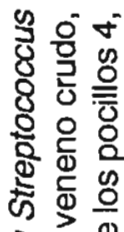

ฟั

क्षे

ชิ

. $\frac{2}{5}>\frac{0}{10}$

ㅇํㅇ

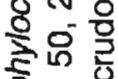

कิ

कั

凹

응 등

क 60

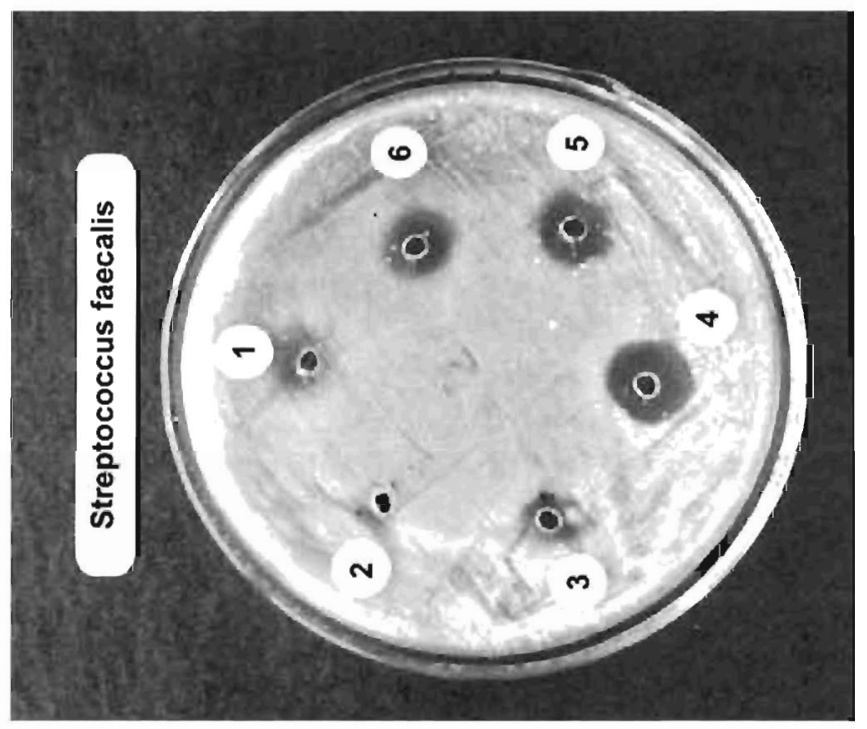

응 옹

잉

茂 8

드응 능

ำㅇํㅇ

웡 응

ต

ब

刃 08

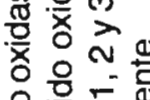

은 흔 흐

曲 응

읕 융

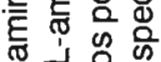

4 园

ปั

웡

음 m옹

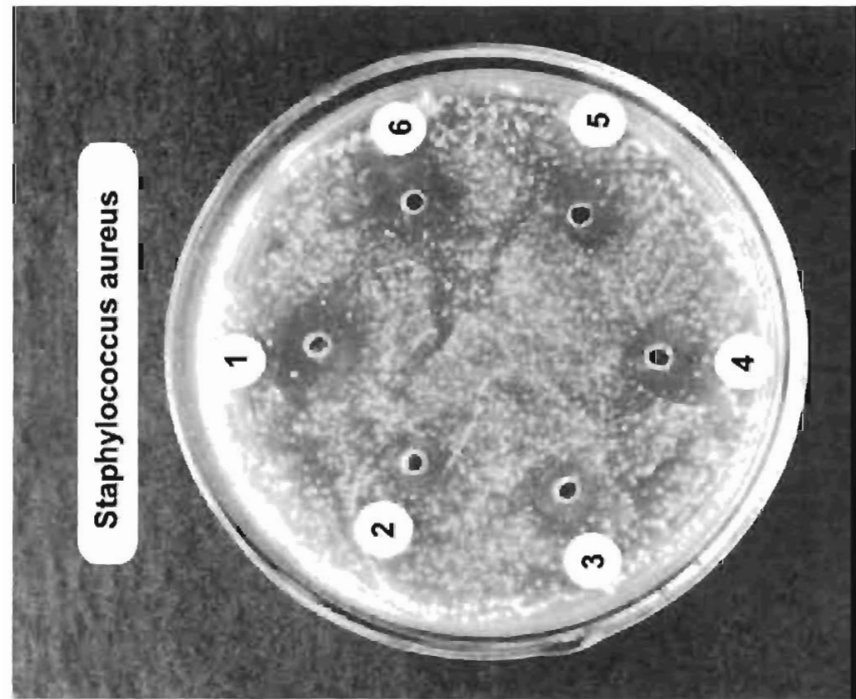

항ㅇㅇㅇ

을 온 응

Ф 5

ब) ब市

ه 8 .

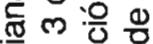

离命品

유

可宁

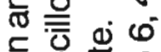

:응 음

응으웜

क

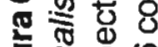

需

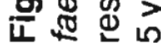


(Stiles et al., 1991). La acción antibacteriana de la L-aminoácido oxidasa es atribuida al peróxido de hidrógeno generado como producto durante la desaminación aeróbica de los Laminoácidos, ya que otras enzimas como la glucosa oxidasa (Roberts et al.,1943) y la xantina oxidasa (Green y Pauli,1943), que también liberan peróxido de hidrógeno durante la oxidación de sus substratos, también tienen efecto antibacteriano. No obstante la Daminoácido oxidasa, que también libera peróxido de hidrógeno, no ostenta dicho efecto, lo que ha sido atribuido a su tendencia a polimerizar, lo cual interfiere con la obtención de una concentración letal de peróxido de hidrógeno (Meister y Wellner,1963).

\section{LITERATURA CITADA}

Andrews, P. 1964. The gel filtration behaviour of protein related to their molecular weight over a wide range. Biochem. J.91:222.

Avrameas, S. y J. Uriel. 1965. L-amino acid oxidase, Toxicon 261:584.

Azañero, M. 1996. Caracterización de una enzima fibrinogenolitica del veneno de Bothrops brazili 'jergon Shushupe' y su comparación con la estreptoquinasa de Sireplococcus. Tesis para optar al Título Profesional de Biólogo, UNMSM.

Buckey. E. y N. Porges. 1956. Venoms. American Association of the Advancenent of Science, II. ed. 2295-302.

Coles, C.; D. Edmondson y T. Singer. 1980. Mechanism of the reversible activation-deactivation of Iamino acid oxidase. Flavins and flavoproteins. Tokio. Japan Scientific Press, 101-105.

Dekok, A. y A. Rawitch. 1969. Studies on 1-amino acid oxidase II: Dissociation and characterization of its subunits. Biochemistry. 8: 1405-1410.

Dekok, A. y C. Veeger. 1968. Sudies on 1-amino acid oxidase II. Effects and the competitive inhibitors. Biochimica et biophysica acta. 133: 345 .

Donlon, J. y P. Fottrell. 1971. Quantitative determination of intestinal peptide hydrolase activity. Clin. Chim. Acta. 33:345.

Dos Santos, M.; L. Ferreira; W. Dias Da Silva y F. Hurtado. 1993. Caracterización de las actividades biolögicas de los venenos "amarillo" y "blanco" de Crotalus durissus ruruma compara. dos con el veneno de Crotalus durissus terrificus. Toxicon, 31:1.459-1470.
Dubois, K.; J. Gilles; P. Hamilton; P. Rebers y F. Smith. 1956. The phenol-sulfuric acid reaction for carbohydrates. Anal. Chem. 28:3350.

Green, E. y R. Pauli, 1943. Xantine oxidase. Pro. Soc. Exp. Biol. And Med. 54:148.

Grove. D. y W. Randall. 1955. Assay of antibiotics. Medical Enciciopedy, New York, $1^{\text {? ed , }}$ pp.78-86.

Iwanaga, S. y T. Suzuki. 1979. L-amino acid oxidase. Handbook of experimental Pharmacology: Snake venoms, 52:65.

Li, Z-Y.; T. Yu y E. Liam. 1994. Purification and characterization of L-amino acid oxidase from King Cobra (Ophiophagus hannan) venom and its effects on human platelet aggregation. Toxicon. 32: 1349-1358.

Liman, J.; G. Cahuana; F. Lazo; O. Málaga; E. Escobar y A. Yarlequé. 1996. Aislamiento y caracterización de proteínas coagulantes de los venenos de Bothrops brazili y Bothrops bilineatus. Libro de resúmenes $V$ Reunión cientifica, ICBAR, UNMSM .

Lowry, O.; N. Rosebrough; A. Fart y R. Randall. 1951. Protein measurement with the folin phenol reagent. Joumal of biology chemistry. 193: 265-275.

Meister, A.1965. L-amino acid oxidase. Biochemistry of the aminoacids. New York. Edit. Academic Press, 2ad, 3044-310.

Meister, A. y D. Wellner. 1963. The Enzymes. Comp: Bojer. P., Lardy. H. \& Myrback. K. New York, Edir. Academic Press, 13. ed. p.26.

Minton. A. y R. Minton. 1970. L-amino acid oxidase. Venomous reptils. New York, Edit. Scribners, 1". ed. 195-199.

Nakano, M.; M. Saga y Y. Tsutsumi. 1969. Distribution and immunochemical properties of rat kidney 1-amino acid oxidase, with a note on peroxisomes. Biochimica el biophysica acta 185 (185): $19-30$.

Ouchterlony, O. y L. Nilsson. 1986. Immunodifussion and immunoelectrophoresis. Handbook of experimental immunology, Oxford, Blakwell Scientific Publications $4^{1}$. ed, 1, pp.32.1-32.50.

Page, D. y R. Van Etten. 1971. L-amino acid oxidase II. Deuterium isotope effects and the action mechanism for the reduction of I-amino acid oxidase by L-leucine. Biochimica et biophysica acta, 227:16-31.

Parikh, J.; J. Greenstein; M. Winitz y S. Bimbaum. 1951. Optically pure preparation of the aminoacids. Journal of Biology Chemistry, 193:265-275.

Roberts, E.; C. Cain; R. Muir; F. Reithel; W. Gaby; J. Bruggen; D. Homan; P. Katzman; R. Jones y E. Doisy. 1943. The ghucose oxidase. Journal of biology chemistry. 147:47.

Sanchez, E. y A. Magalhaes. 1991. Purification and characterization of L-amino acid oxidase of 
Lachesis muta venom. Brazilian. J. Med. Biological. Res. 24:255.

Singer, T. y E. Kearney. 1950. The L-amino acid oxidases of snake venoms II. Arch. Eiochem Biophys. 29:190-209.

Skarnes, R. 1970. L-amino acid oxidase, a bactericida system. Nature. 225:1073.

Stiles, B.; F. Sexton y S. Weinstein. 1991. Antibacterial affects of different snake venoms: purification and characterization of antibacterial proteins from Pseudechis australis (Australian king brown or mulga snake) venom. Toxicon, 29:1129-1141.

Styblova, Z. y F. Kornalick. 1967. Enzimatic properties of Helodema suspectum venom. Toxicon 5 (139): 139.

Tu, A. 1977. L-amino acid oxidase. Venoms: Chemistry and Molecular Biology. Edit John Wiley \& Sons , 1*. ed, 93-94.

Warburg, O. y W. Christian. 1941. Isolierung and cristallisation of Garungs ferments. Biochem. Z. 310:384-421.

Warren, L. 1959. The thiobarbituric acid assay of sialic acid. J. Biológicas. Chem. 234 (8):1971-1975.

Weber, $\mathrm{K}$ y M. Osborn. 1969. The reliability of molecular weight determinations by dodecil sulphate polyacrylamide gel electrophoresis. Joumal of Biology Chemistry. 244:4406-4412.

Winzler, R. 1955. Determinations of serum glycoproteins. Methods of Biccnemical Analysis. 2:279-311.

Worthington Biochemica! Corporation. 1977. L-amino acid oxidase. The Worthington Manual Enzymes reagents related biochemicals. New Jersey. p. 49.

Yarlequé, A.; J. Cárdenas, E. Escobar y S. Gutiérrez. 1997. Some biochemical properties and antibacterial action of L-aminoacid oxidase from Peruvian snake venoms. Fourth Asia Pacific Congress on Animal, Plani and Microbal Toxins. Toxicon 35 (4):489.

Zeballos, J. 1996. Aislamiento y caracterización parcial de la fosfolipasa A presente en el veneno de la serpiente Bothrops brazili (Jergon Shushupe')". Tesis para optar al Título Profesional de Biologo, UNMSM. 